\title{
Melanoma Metamorphoses: Advances in Biology and Therapy
}

\author{
Arthur E. Frankel* and Eugene P. Frenkel
}

University of Texas Southwestern Medical Center at Dallas, Internal Medicine, TX 75390, USA

\begin{abstract}
Melanoma is a malignancy of melanocytes of cutaneous, uveal or mucosal origins. This review discusses advances in biology and new approaches in staging and advanced disease therapy. The role of UVA light in dark reactions generating dioxetane products and cyclobutane pyrimidine dimers in melanoma genesis is detailed. Utility of screening programs and prevention with enhanced UVA blockers is included. Different staging algorithms for cutaneous, uveal and mucosal melanomas are described. Advances in adjuvant radiotherapy and immunotherapy are noted. Stereotactic radiotherapy for brain metastases and metastasectomy for oligometastatic disease has impacted the natural history of this disease. While combined BRAF and MEK inhibition for BRAF mutant melanoma patients have produced durable remissions, relapse is frequent and due to multiple genetic mechanisms. Immunotherapy with anti-CTLA4 and anti-PD1 immune checkpoint blockers also yields long-term responses, but there remains many patients unresponsive to immune checkpoint blockade or whom develop resistance. Host and tumor-specific resistance mechanisms are explored. Some new areas of melanoma research include nanoparticle fluorescence surgical imaging for regional and metastatic disease, tumor gene expression profiling to predict BRAF inhibitor resistance, combination of ion channel blocker with MEK inhibitor for wild-type BRAF metastatic melanoma, establishment of the innate immune signalling pathway for stereotactic radiotherapy of melanoma, and testing of IDO inhibitors with anti-PD1 inhibitors in metastatic melanoma.
\end{abstract}

Keywords: Melanoma biology; Melanoma targeted therapy; Melanoma immunotherapy

Melanoma is a malignancy of melanocytes of cutaneous, uveal, or mucosal origins. This review discusses advances in biology and new approaches in staging and advanced disease therapy.

\section{Incidence}

Melanoma is occurring with a startling and increasing incidence in the United States, Europe, and Australia. Two percent of all Americans will develop melanoma in their lifetime, and a million Americans are living with a diagnosis of melanoma. With an annual rate of 75,000 cases/year or 22/100,000 people, cutaneous melanoma represents $4.5 \%$ of all cancer cases. The incidence of melanoma has tripled between 1975 and 2012 [1]. Annual rates for uveal and mucosal melanomas are 1,200 and 600 cases/year and have not increased over time [2,3].

\section{Risk Factors}

Risk factors for cutaneous melanoma have been well described and a partial risk algorithm is available [4]. Higher risk ratios are seen for people with xeroderma pigmentosum (2000x), FAMMM syndrome$133 \mathrm{x}$, previous melanoma-12.4x, multiple nevi-5.5x, tanning bed use$3.9 \mathrm{x}$, Parkinson's disease- $3.6 \mathrm{x}$, blond or red hair- $1.8 \mathrm{x}$, family history of melanoma-1.7x, pale or freckled skin-1.6x, blistering sunburn history-1.3x [5-8]. Interesting correlations have been observed between melanoma and airline pilot/crew occupation, immunosuppression, and living in lower latitudes [9-13]. Dietary factors have been extensively studied with equivocal results- the most recent implicate beneficial effects of vitamin $\mathrm{D}$ containing foods, butter, and oregano on melanoma incidence $[14,15]$. There is a strong interaction between genetic presence of DNA repair errors and UV exposure [16-18].

\section{Etiology}

More is known about the photochemistry and genetics leading to cutaneous melanoma than about the origins of uveal or mucosal melanomas. The solar fusion reaction generating helium yields highly energetic photon products that excite the coronal hydrogen electron to higher energy states. When these electrons return to lower quantum states, light photons are emitted towards the earth including UVA, UVB, UVC and visible light. Water molecules and other particles in the atmosphere block UVC and some UVB. Most UVA and visible light reaches the earth and humans. Primitive humans were protected from excessive photo-damage by hair or eumelanin skin pigmentation. However, human migration, pigmentation gene mutations, cultural dress norms and recreational activities have led to heightened skin exposure to UVA. A long-known paradox was the association of melanoma with UVA rather than UVB light. Only UVB light has the energy necessary to directly induce cyclobutane pyrimidine dimers. These DNA adducts are the precursors for the genetic lesions associated with melanoma. In the last year, Brash and colleagues at Yale discovered a pheomelanin-dependent pathway that converts UVA exposure into melanocyte cyclobutane pyrimidine dimers [19]. UVA induces expression of nitric oxide synthetase, NADPH oxidase and melanin synthetases. These enzymes produce nitric oxide, superoxide, peroxynitrite, and pheomelanin in the cytosol and melanosomes, respectively. These products combine to yield melanin degradation products and dioxetane-containing molecules in the cytosol (Figure 1) [20]. Dioxetane products persist and diffuse to the nucleus where they undergo thermolysis to excited-state triplet carbonyls-n- $>\pi^{*}$. This species participates in Dexter triplet-triplet energy transfer to

*Corresponding author: Frankel AE, Professor, University of Texas Southwestern Medical Center at Dallas, Internal Medicine, 5323 Harry Hines Blvd, Dallas, TX 75390, USA, Tel: + 214-648-1579; Fax: + 214-648-1579; E-mail: arthur.frankel@utsouthwestern.edu

Received November 16, 2016; Accepted January 25, 2017; Published January 27,2017

Citation: Frankel AE, Frenkel EP (2017) Melanoma Metamorphoses: Advances in Biology and Therapy. J Cancer Sci Ther 9: 325-335. doi: 10.4172/1948-5956.1000437

Copyright: @ 2017 Frankel AE, et al. This is an open-access article distributed under the terms of the Creative Commons Attribution License, which permits unrestricted use, distribution, and reproduction in any medium, provided the original author and source are credited. 


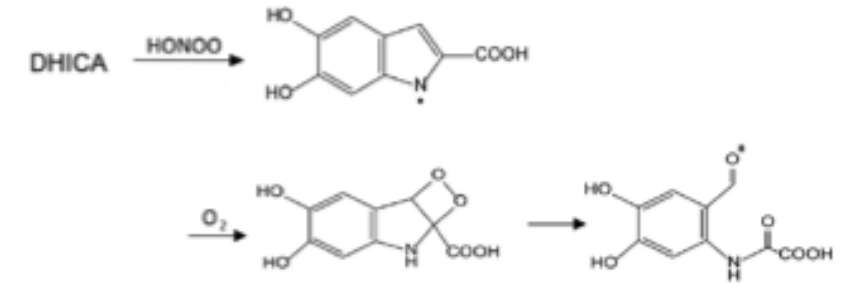

Figure 1: UVA light produces melanocyte dioxetane containing products that diffuse into nucleus, generate excited state carbonyls, and modifies DNA. Cyclobutane pyrimidine dimers result. After deamination, translesional nucleotide repair by $\mathrm{pol} \eta / \mathrm{pol} \zeta$ generate $\mathrm{C}->\mathrm{T}$ mutations [107].

converts DNA--> $\pi^{*}$ to cyclobutane pyrimidine dimers- $\pi^{*}->$ strained $\sigma$. Uveal melanomas have been associated with blue light, and mucosal melanomas with formaldehyde exposure [21,22].

Somatic cell DNA sequencing revealed a dominant mutation signature associated with melanoma-Signature 7 due to $\mathrm{C}>\mathrm{T}$ substitutions on the untranscribed strand. This signature is caused by cyclobutane pyrimidine dimer repair by transcription-coupled nucleotide-excision repair [23]. BRAF mutations occur from errorprone replication repair by pol $\eta / \mathrm{pol} \zeta$ from nearby CPD formation [24]. Founder mutations occur in mitogen-activated protein kinaseMAPK proliferation control genes yielding four melanoma subtypesmutant BRAF, mutant RAS, mutant NF1, and triple wild-type containing KIT, GNAQ/11 $[25,26]$. Further mutations in cell cycle checkpoint-CDKN2A, immortalization-TERT promoter, and other pathway genes-p53, PTEN, BAP1, ARID1, YAP1 provide a growth advantage [27-29]. In fact, a careful study of multiple biopsies of evolving melanocytic lesions showed progression from BRAF/NRAS/ NF1 mutations nevus to pTERT/CDKN2A/ARID1A mutations in in situ melanoma to PTEN/P53/YAP1/BAP1 invasive melanomas [30]. Acquisition of a neural crest stem cell phenotype with LOX10 and SETDB1 overexpression further contributes to invasive melanoma [31,32]. GNA11/Q and c-KIT are preferentially mutated in uveal and mucosal melanomas, respectively. Melanoma has the highest mutation burden of any cancer.

\section{Screening and Prevention}

Because of the location of cutaneous melanomas, screening for early detection is feasible, non-invasive, and relatively inexpensive. Visual examination focuses on the "ABCDE" mnemonic-asymmetry, border irregularity, color variegation, diameter $>6 \mathrm{~mm}$, and evolution with rapid morphologic changes [33]. However, observer training is required to distinguish benign from malignant moles with the best exam sensitivity and specificity achieved by dermatologists. Further, more and less thick lesions are discovered by more frequent examinations with yearly better than biannual better than every five years better than once only. Ophthalmology exams are needed to screen for uveal melanomas [34]. There is no effective screening for mucosal melanomas. Results are improved with addition of supplemental dermatoscopy and total body photography [35]. In a meta-analysis, dermatoscopy increased sensitivity of diagnosis from $74 \%$ by naked eye to $90 \%$ with the instrument without a significant decrease in specificity. Addition of total body photography led to removal of thinner melanomas (note change in size of lesion as shown below). Further, $40 \%$ of discovered lesions were not being followed by visual or dermatoscopic surveillance [36]. There are sobering limitations. Nodular melanomas grow rapidly and may advance to late stage between examinations complicating periodic monitoring. Amelanotic and desmoplastic melanomas lack most of the ABCDE features often leading to delayed diagnosis. Nevertheless, screening saves lives as demonstrated in the Schleswig-Holstein study with a single standardized whole-body examination where a $48 \%$ decline in melanoma mortality was reported compared to unscreened adjacent regions of Germany [37].

Preventive measures centre on reduced UV skin exposure with avoiding sun exposure between $10 \mathrm{AM}$ and $2 \mathrm{PM}$, wearing light colored, dry, synthetic material, high ultraviolet protection factorUPF clothing with UV absorbers in laundry detergent, wide-brimmed hats and applying high sun protection factor-SPF UVA-UVB broad spectrum sunscreens in adequate amounts-one teaspoon each for face, neck, and two teaspoons each for abdomen, back and limbs and frequency every 2-3 h $[38,39]$. UVB blockers include physical barrierstitanium dioxide and chemical absorbers-oxybenzone. UVA blockers include the chemicals-avobenzone/octocrylene, ecamsule, silatrizol, and bemetrizinol. Only the avobenzone/octocrylene is available in U.S [40]. Uveal melanoma protection includes orange/yellow sunglasses and blue light-blocking lens replacements [22].

\section{Diagnosis}

A punch or excisional biopsy with histologic and sometimes immunohistochemical analysis is required for cutaneous melanoma diagnosis [41]. Morphological/histological findings of cutaneous melanomas include pagetoid cells or atypical cells with branching dendritic structures, broadened honeycombed pattern or cerebriform clusters $[42,43]$. Melanomas are assigned to superficial spreading melanoma, lentigo maligna, nodular melanoma and desmoplastic melanoma. Cytologically atypical melanocytes in epidermis and dermis with mitoses and necrosis or inflammation are seen. Desmoplastic melanomas have abnormal melanocytes surrounded by fibrous tissue [44]. Markers for melanocytic differentiation include HMB45, Melan-A/Mart, tyrosinase, MITF and SOX10. Both radial growthsuperficial spreading melanoma and vertical growth-nodular melanoma predominant patterns are seen. Uveal melanomas are diagnosed by ophthalmoscopy and scans rather than biopsy. Mucosal melanomas require tissue biopsy confirmation for diagnosis.

\section{Staging}

For cutaneous melanomas, patient history, the patient's gender and age are determined. The physical exam and punch biopsy provide evidence of location of disease (extremity or axial), ulceration, tumor thickness, and mitotic rate. Once the biopsy confirms the diagnosis, blue dye + radiocolloid (e.g., ${ }^{99 \mathrm{~m}} \mathrm{Tc}$ tilmanocept) infusion with sentinel node biopsy is performed [45]. For clinically positive nodal metastases and for mucosal or uveal melanomas, PET/CT and brain MRI scans are done to assess visceral metastases. Tumor specimens should be sent for oncogene studies-BRAF or c-KIT for node positive cutaneous melanomas or mucosal melanomas, respectively. Several prognosis algorithms are available online for cutaneous melanomas including http://melanomaprognosis.org and www.melanomacalculator.com $[46,47]$. As noted below, cutaneous melanoma-free survival is shortened by older age, male gender, thicker tumor, tumor ulceration, measurable mitoses $/ \mathrm{mm}^{2}$, positive sentinel nodes, multiple or macroscopic nodal metastases, any distant metastases-particularly non-lung visceral lesions, and poor prognosis gene expression profile (Figure 2) [4852]. The 31-gene expression panel of Castle Biosciences combined with sentinel node status was the most accurate predictor of diseasefree, metastasis-free and overall survival. Staging provides important 
information to patients for planning definitive and adjuvant therapies and deciding on frequency and type of monitoring. Uveal melanoma survival is lower for thick or wide lesions, ciliary body or extraocular extension, bad prognosis gene expression profile or with metastases identified by PET, CT or MRI scans (Figure 3) [53,54].

Mucosal melanoma prognosis depends on tumor size, organ site, and presence of node or visceral metastases. Tumor thickness $>1 \mathrm{~mm}$, $>3 \mathrm{~cm}$, and $>3 \mathrm{~cm}$ for female genital tract, head and neck and GI tract, respectively, leads to shortened survival (Figure 3) [55]. Non-vulvar organ site is worse [3]. Positive nodes or visceral metastases portend short survival.

\section{Local Therapy}

Cutaneous melanoma local control is achieved by excisional surgery. For cutaneous melanomas $\leq 1 \mathrm{~mm}$ thickness, $1 \mathrm{~cm}$ margins are sufficient. For melanomas between 1 and $2 \mathrm{~mm}, 1-2 \mathrm{~cm}$ margins are done. For melanomas $\geq 2 \mathrm{~mm}$ thickness, $2 \mathrm{~cm}$ margins are required. These excision margins yield a $4 \%$ local recurrence rate that is not improved by wider margins based on multiple randomized trials [56].

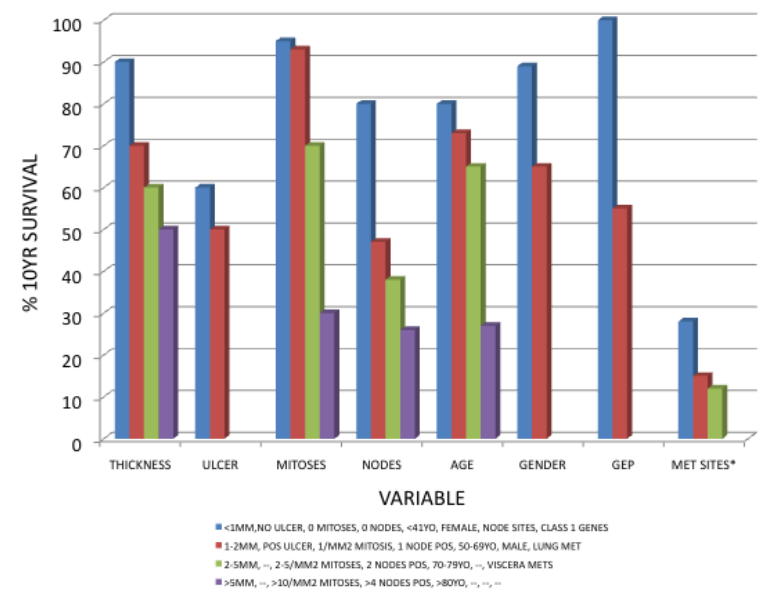

Figure 2: Cutaneous Melanoma Prognosis.

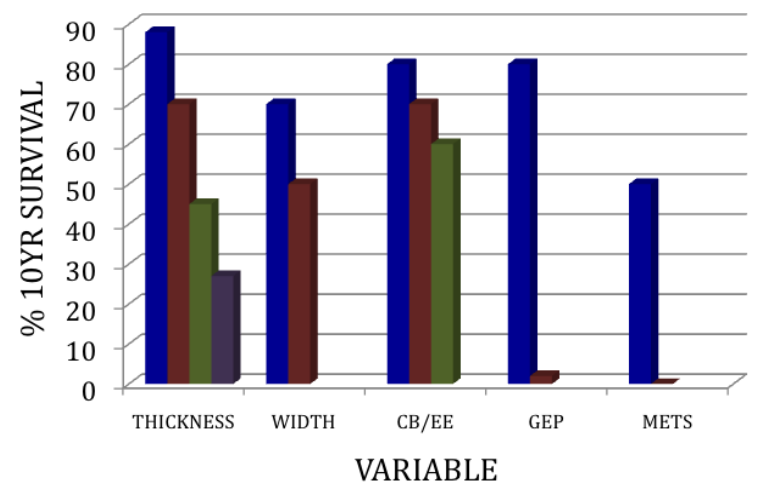

- <6MM, $<2 X$ WIDTH, NO CB OR EE, GEP CLASS 1 , NO METS - $<9 M M,>2 X$ WIDTH, CB, GEP CLASS 2, POS METS $<12 \mathrm{MM}, \cdots, \mathrm{EE}, \cdots, \cdots$

Figure 3: Uveal Melanoma Prognosis.
Uveal melanomas of $\leq 18 \mathrm{~mm}$ diameter and $\leq 12 \mathrm{~mm}$ thick are treated with plaque brachyradiotherapy, stereotactic radiosurgery or proton beam radiotherapy with retention of eyesight in most cases and $2 \%, 2 \%$ and $5 \%$ local recurrence rates, respectively $[57,58]$. The Collaborative Ocular Melanoma Study established the relative equivalence of ${ }^{125} \mathrm{I}$ plaque brachyradiotherapy to enucleation for local and systemic disease control [59]. Some centers consolidate treatment with transpupillary thermotherapy or sector photocoagulation. Intravitreal anti-VEGF or periocular triamcinolone injections may be used to minimize vascular complications. For uveal melanomas $>18$ $\mathrm{mm}$ diameter and $>12 \mathrm{~mm}$ thickness, enucleation is performed. A minimal manipulation technique is done, and a hydroxyapatite globe inserted.

Mucosal melanoma primary therapy includes local excision with 2 $\mathrm{cm}$ margins for disease confined to the vulva [60]. For advanced disease, pelvic exenteration is done. Sinus melanomas are treated with wide local excision followed by external beam radiotherapy (Ming, 2014). Anal melanomas may be treated by either wide excision or abdominoperineal resection without differences in five-year survival [61].

\section{Regional Therapy}

Cutaneous melanomas have a $20 \%$ frequency of nodal and regional subcutaneous involvement, and efforts to control regional disease are an important part of care. Sentinel node sampling is done for cutaneous melanomas but not uveal or mucosal melanomas. If either positive sentinel nodes or clinically enlarged nodes are found, lymphadenectomy is carried out. Dissections are limited to the target lymph node basincervical, axillary, inguinal, iliac, epitrochlear or popliteal. In the setting of microscopically positive sentinel nodes, lymphadenectomy results in improved regional control, and for intermediate thickness primary tumors (1.2-3.5 mm), better overall survival [62]. However, lymphadenectomy is associated with a significant morbidity rate of $23 \%$. Patients experience lymphedema, seroma formation, dysesthesias, and motor dysfunction. The post-adenectomy recurrence rate is $20 \%$ [63]. The German DeCOG-SLT trial demonstrated no superiority for lymphadenectomy in sentinel node positive patients and concluded adenectomy was not indicated for $\leq 1 \mathrm{~mm}$ micrometastases [64]. An ongoing MSLT-2 randomized clinical trial is comparing immediate lymphadenectomy for sentinel node positive disease versus ultrasound monitoring followed by lymphadenectomy on clinical recurrence. This study will address the value of early lymphadenectomy for all patients. For patients post-lymphadenectomy with positive parotid node or extra-nodal tumor spread or $\geq 3 \mathrm{~cm}$ cervical nodes or $\geq 4$ $\mathrm{cm}$ axillary/inguinal nodes or $\geq 2$ involved cervical/axillary nodes or $\geq 3$ involved inguinal nodes, adjuvant 48 Gy external beam radiation over 20 fractions over 4 weeks, was well tolerated and reduced regional relapse from $55 \%$ to $25 \%$ [65]. There is no survival advantage for lymphadenectomy in vulvar, uveal, sinus or anal melanoma patients. Sinus melanoma adjuvant radiotherapy reduces regional recurrence two-fold [66]. Anal melanoma adjuvant radiotherapy to the extended field after wide excision reduces regional recurrence three-fold but does not impact distant relapse and may be associated with severe toxicities including lymphedema and proctitis.

\section{Adjuvant Systemic Therapy}

Melanoma-related death is due to systemic metastases present at diagnosis. After local-regional therapy, adjuvant therapy to prolong disease-free survival and improve overall survival has been tested. The only FDA approved agents are interferon $\alpha 2 b$ and pegylated interferon 
$\alpha 2 b$. Interferon- $\alpha 2 b$ is a secreted glycoprotein that binds cell surface receptors with two distinct subunits. The bound complex phosphorylates Janus kinase 1-JAK1 and tyrosine kinase 2. Phosphorylated JAK phosphorylates the cytoplasmic transcription factors signal transducers and activators of transcription 1 and 2-STAT1/2. STAT1/2-P attaches to interferon-stimulated gene factor 3 and translocates to the nucleus where it reacts with interferon-stimulated response elements in the promoters of interferon-responsive genes and activates transcription promoting a pro-inflammatory state [67]. Meta-analyses of multiple randomized trials showed a one-year improvement in disease-free survival and a $3 \%$ benefit in overall survival for interferon versus placebo [68]. The subset of patients with ulcerated melanomas either $\geq$ $2 \mathrm{~mm}$ or with microscopic nodal disease also had a ten months diseasefree survival benefit but a $20 \%$ benefit in overall survival for interferon $[69,70]$. Interferon toxicities are fatigue, anorexia, hepatotoxicity and flu-like symptoms and are controlled by dose modification and aggressive symptom control [71,72].

Based on the success of interferon, adjuvant ipilimumab (an anti-CTLA-4 immune checkpoint antibody discussed in more detail below) has been tested in node positive patients in U.S. and European randomized trials compared to interferon and placebo, respectively. Preliminary results of the European study at 2.5 years of follow-up show an ipilimumab nine months improvement in disease-free survival [73]. Similar to interferon, the greatest benefit was in ulcerated primaries with microscopic nodal involvement. Survival data is not yet available. Ipilimumab toxicities led to half of patients discontinuing treatment within three months. The most common side effects were autoimmune hepatitis, colitis and hypophysitis. The FDA approved adjuvant use of ipilimumab $10 \mathrm{mg} / \mathrm{kg}$ q 3 wk x 4 then $\mathrm{q} 12$ wks $\mathrm{x} 3$ years for node positive melanoma post-lymphadenectomy on $10 / 28 / 2015$. An ongoing SWOG 1404 trial will compare high dose interferon, ipilimumab and pembrolizumab for adjuvant therapy of high-risk, resected stage III/ IV melanomas.

\section{Therapy of In-transit/Satellite Metastases}

Isolated loco-regional skin metastases occur in $7 \%$ of melanoma patients and are associated with a $50 \%$ ten-year survival $[74,75]$. Thus, in-transit or satellite disease has an intermediate prognosis-some patient live decades with only regional recurrences and other patients rapidly progress with systemic metastases and death. The diagnosis is based on location of skin lesions between the primary tumor and draining lymph node basin. Possible causes include unique tumor genetics or lymphatic tumor emboli. Therapies yielding the highest disease control rate include intra-lesional recombinant interleukin-2 or talimogene laherparepvec genetically engineered herpes simplex virus, $\mathrm{CO}_{2}$ laser lesion ablation, and hyperthermic or normothermic isolated melphalan or temozolomide limb perfusion (Andtbaca, 2015;) [7678]. Durable remission rates are $40 \%, 16 \%, 24 \%$ and $25 \%$, respectively. Side effects of interleukin-2, herpes simplex virus and $\mathrm{CO}_{2}$ laser are local inflammation, fevers, and fatigue. Isolated limb perfusion may be associated with muscle injury or, rarely, limb loss. Intra-lesional therapies have been associated with durable control of treated lesions and regression of other metastases suggesting a prolonged, abscopal effect.

\section{Metastasectomy for Oligometastatic Disease}

Approximately, one-fifth of metastatic melanoma patients have a few indolent lesions limited to one to three organs [79]. A review of fourteen clinical trials showed of patients with isolated skin/soft tissue/node, lung, or non-lung viscera metastases, 58\%, 23\% and 15\% of patients, respectively, had disease amenable to metastasectomy. Compared with control patients matched for number of metastases and number of organ systems affected, metastasectomy yielded a median survival of 16 months and a $21 \%$ four-year survival versus 7 months and $7 \%$ survival in the control population in the MSLT-1 trial [80]. Best results were seen for skin/soft tissue/nodal metastatic patients with a hazard ratio of 0.24 favoring surgery. An international phase III trial (NCT01013623) is randomizing patients with $\leq 6$ metastases in $\leq 3$ organs to surgery versus systemic medical therapy alone to confirm the survival advantage of metastasectomy and identify patient subsets with maximal benefit.

\section{Radiation Therapy for Metastatic Melanoma to Brain}

Close to half of metastatic melanoma patients develop symptomatic brain metastases, and these lesions contribute to death in a fourth of all metastatic melanoma patients [81]. Unless surgery is needed for diagnosis, stereotactic radiosurgery-SRS is the established treatment for single and multiple brain metastases. 20-24 Gy single fraction or 25$30 \mathrm{~Gy}$ multiple fractions is administered. SRS has been shown to yield equal overall survival with improved neurocognitive function relative to whole brain radiation therapy-WBRT [82]. Frequent brain MRIs are employed to monitor for recurrence. $45 \%$ of SRS-treated patients required further brain radiation-either additional SRS or WBRT [83]. Death due to brain disease occurred in $11 \%$ of patients [84]. A graded prognostic assessment tool is available at www.brainmetgpa.com and provides melanoma median survival based on performance status and number of brain lesions [85]. A rare side effect (2\%) is radiation necrosis that can be treated with corticosteroids, bevacizumab and/or surgery.

\section{Chemotherapies for Metastatic Melanoma}

Cytotoxic chemotherapies selectively target proliferating cells. The rationale is that tumor cells divide more frequently than normal tissues. While likely true for many hematologic malignancies and germ cell tumors, most tumors including melanomas have variable growth fractions. Thus, melanoma chemotherapy remissions are uncommon and normal tissue toxicities including myelosuppression and GI toxicities are frequent. A range of single agents and combination chemotherapies have been tested yielding response rates of $10-26 \%$, progression-free survivals-PFS of 2-7 months, and overall survivals of 6-12 months (Figure 4) [86-90].

Because of the low response rates and minimal impact on overall

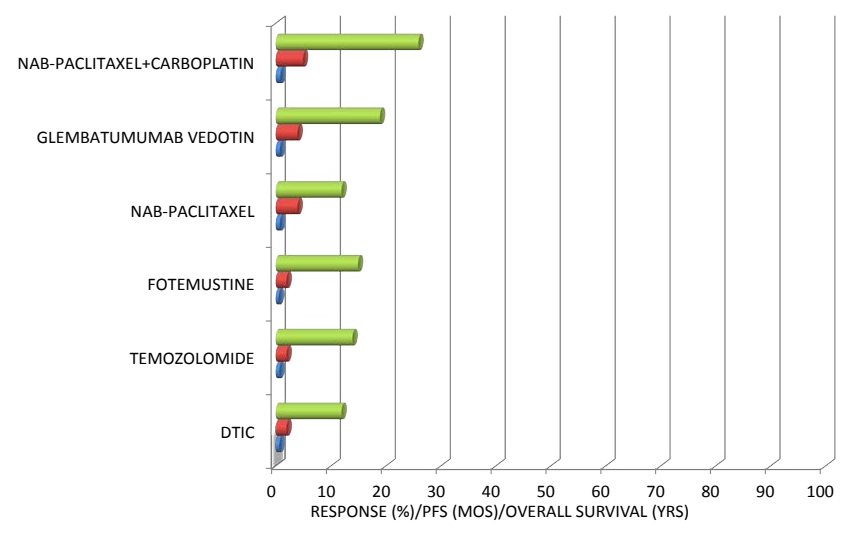

Figure 4: Metastatic melanoma chemotherapy regimens. 
survival, efforts have been made to identify predictive biomarkers of response. $\mathrm{O}^{6}$-methylguanine DNA methyltransferase enzyme-MGMT repairs DTIC/temozolomide/fotemustine DNA damage and blocks cytotoxicity. Methylation of the MGMT promoter inhibits RNA and protein expression and enhances sensitivity to drug killing. MGMT promoter methylation was an excellent predictor of melanoma temozolomide response [91]. miR-659-3p microRNA expression controls expression of several melanoma anti-apoptosis genes and was associated with response to carboplatin plus paclitaxel [92]. gpNMB protein is the target of glembatumumab and gpNMB expression may predict response to glembatumumab vedotin. Additional confirmatory studies for each will be needed. These may permit better patient selection for chemotherapy agents. Nevertheless, toxicities are significant. Myelosuppression/GI toxicities, neuropathy, and rash were seen with temozolomide/ DTIC/fotemustine/carboplatin, nabpaclitaxel, and glembatumumab, respectively. While greater response rates, progression-free survival rates and overall survival were seen for combination regimens, frequency and severity of side effects worsened. Most of the studies were phase II, and response rates and response durations were less when the same drugs were tested in phase III trials. No evidence has been obtained that any one of the chemotherapy regimens is superior to others or to best supportive care. At present, our first approach at UTSW is to treat first with pathway inhibitors or immune modulators (see below) or enter eligible patients on novel clinical trials and reserve chemotherapy for salvage.

\section{Pathway Inhibitor Therapy for Metastatic Melanoma}

All living cells communicate with their environment via hormones and receptors. Mammalian cells possess cell surface receptors that transmit and amplify signals into the cytoplasm by secondary messengers including kinases. The signals modify gene transcription and translation, alter protein structure and change metabolism. Thus, cells are poised to adjust to changes in the extracellular milieu. Mutations in pathways can lead to neoplastic cell proliferation, survival and/or migration. Melanomas frequently have mutations in the mitogen-activated protein kinase-MAPK pathway. Small molecule compounds that block constitutive activation of pathway elements were used successfully in patients with BRAF V600E/K, NRAS and cKIT mutant metastatic melanomas. Further, some clinical benefit has occurred with VEGF inhibition in LDH elevated, non-lung viscera metastatic melanomas.

Half of cutaneous metastatic melanoma patients have BRAF $\mathrm{V} 600 \mathrm{E} / \mathrm{K}$ and have been treated with combinations of BRAF and MEK inhibitors such as dabrafenib/trametinib, vemurafenib/cobimetinib and encorafenib/binimetinib [93]. Response rates are 75\% with PFS of 1 year and median overall survival 2 years [94]. Toxicities are pyrexia, nausea, diarrhea, rash, fatigue, edema, photosensitivity, central serous retinopathy, transaminasemia. The greatest problem is drug resistance due to MAPK reactivation or up-regulation of the PI3K/PTEN/AKT or NF- $\kappa B$ pathways. MAPK reactivation occurred with MEK1/2 mutations, RAC1 mutation, MAP3K8 or CRAF expression, BRAF amplification, truncated BRAF variants, or NRAS or KRAS mutations [95-98]. Compensatory PI3K/PTEN/AKT pathway activation was seen with PI3KCA, AKT1/3, PIK3R2, PTEN, PHLPP1 mutations, PDGFR $\beta$ or RhoB expression or stromal HGF expression $[99,100]$. Numerous in vitro and in vivo mouse melanoma models have shown synergistic cytotoxicity and anti-tumor efficacy of combining MAPK pathway inhibitors with PI3K/AKT inhibitors and clinical studies of these combinations are ongoing [101-104]. NF- $\kappa B$ activation and MITF amplification also produced MAPK-independent resistance $[105,106]$.
Twenty percent of cutaneous melanomas have NRAS mutations. The MEK inhibitor binimetinib achieves a 20\% response rate and six-month PFS in NRAS mutant patients (Ascierto, 2013). Fifteen percent of acral and mucosal melanomas possess c-KIT mutations. Imatinib mesylate produces a $33 \%$ response rate, a 4 month PFS, and a 14 month overall survival in patients with c-KIT exon 8,11 or 13 mutations $[107,108]$. Metastatic melanoma patients with non-lung visceral metastases and elevated LDH show increased tumor angiogenesis and improved response to anti-VEGF therapy. Bevacizumab plus carboplatin plus paclitaxel gave a $26 \%$ response rate, 6 month PFS, and 12 month OS that was superior in each case to carboplatin plus paclitaxel alone [109]. For all pathway inhibitors, recurrences are due to branched evolution with multiple different resistance genotypes for each metastasis in a patient.

\section{Immunotherapy for Metastatic Melanoma}

Several factors triggered an interest in immunotherapy for melanoma. First, metastatic melanoma has the highest rate among cancers of spontaneous durable remissions at $0.2 \%$ [110,111]. These regressions are associated with marked tumor lymphocytic infiltration. Second, interferon showed some anti-melanoma activity as noted above. Third, the discovery of the $\mathrm{T}$ cell growth factor, interleukin 2-IL2, and its cloning and expression and purification from $E$.

coli facilitated testing in humans. IL2 binds heterodimeric receptors on cytotoxic T cells and NK cells, generates P-STAT5 and promotes differentiation and proliferation [112]. Rosenberg and others tested high doses of IL2 in metastatic melanoma patients [113]. Patients administered 600,000 IU/kg/IV bolus every eight hours for up to 14 doses in cycles separated by 1-4 weeks achieved a response rate of $16 \%$ including $6 \%$ complete responses-CRs. Remarkably, most of the CRs have remained disease-free for decades. Unfortunately, the treatment is associated with neutrophil paralysis and severe capillary leak syndrome. Toxicities are sepsis, hypotension, uremia, pulmonary edema, hepatic and GI toxicities, thrombocytopenia and 1\% deaths. Prophylactic antibiotics and a stringent protocol for dosing, fluid supplements and pressors have reduced side effect severity [114]. Predictors of CR include N-RAS mutation, better pre-treatment performance status, normal LDH and only skin/subcutaneous metastases [115]. Pretreatment stereotactic body radiotherapy may improve CR rate [116]. Nevertheless, the severe toxicities and limited efficacy discourage most patients from this treatment.

These observations opened the possibility of long-term remissions from expanding cytotoxic $\mathrm{T}$ lymphocytes in patients. However, once reaching the tumor, very few remissions were obtained. The immunosuppressive tumor microenvironment was due in part to local immune checkpoints-CTLA4 blocking CD28 co-stimulation and PDL1 inhibiting T cell activation. Human monoclonal antibodies blocking the immune checkpoints were developed--ipilimumab and tremelimumab for anti-CTLA4 and nivolumab and pembrolizumab for anti-PD1. The combination of nivolumab and ipilimumab--FDA approved $9 / 30 / 15$ produced a $61 \%$ response rate and a 12 months PFS in metastatic cutaneous melanoma. Median OS exceeds two years [117]. Toxicities are severe and common but manageable. Autoimmune complications are seen in most patients and consist of colitis, hepatitis, hypophysitis, dermatitis, and are treated with drug discontinuation, steroids and/or infliximab [118]. Pretreatment low serum VEGF and LDH, NRAS mutation, large mutational load or neoantigen load, tumor $\mathrm{T}$ cell infiltration, viral defense signature, high tumor interferon $\gamma$ mRNA levels, lack of IPRES gene signature, oligoclonal circulating and 
tumor TCR clonality, absence of Wnt/ $\beta$-catenin pathway activation, elevated PD-L1 level, and elevated circulating lymphocyte, monocyte or eosinophil levels predict response (Goldmeyer, 2016) [119-132]. Relapse to anti-PD1 therapy has been linked to loss-of-function mutations in JAK1, JAK2, and beta-2microglobulin [133]. Similar efficacy was observed in acral and mucosal metastatic melanomas, but not in uveal metastatic melanomas [134-136].

Another method to ameliorate the immunosuppressive melanoma microenvironment is intra-lesional injections of modified herpes simplex virus type 1 carrying deletions of virulence genes ICP34.5 and ICP47 and insertion of human granulocyte-macrophage colony stimulating factor, talimogene laherparepvec or T-VEC. T-VEC selectively replicates in melanoma cells and lyses the cells promoting systemic anti-tumor immunity. T-VEC has been given at $10^{6} \mathrm{pfu} / \mathrm{mL}$ and then $10^{8} \mathrm{pfu} / \mathrm{mL}$ up to $4 \mathrm{~mL}$ at 2 weeks intervals for up to 18 months. For patients with subcutaneous and nodal lesions and limited visceral metastases, the response rate was $23 \%$ and median OS was 24 months vs $6 \%$ and 19 months with subcutaneous GM-CSF [137]. T-VEC was FDA approved on 10/27/2015. With these exciting developments, the stage is set for exploratory studies to further improve response rates and response duration in different patient subsets.

\section{Novel Areas of Melanoma Clinical Research}

Preclinical melanoma research employing in vivo models has focused on the syngeneic B16 melanoma in C57BL/6 mice, human melanoma cell lines or patient derived tissue sample xenografts in immunocompromised mice, and genetically engineered mouse models with RAS, p16INK4A, p19ARF, CDK4, p53, RET, BRAF, GNAQ, glutamate receptor GRM1 and/or PTEN mutations [138140]. The syngeneic model and genetically engineered mice models offer metastatic variants including luciferase transformants for live animal imaging. Each model has advantages and disadvantages with similar patient biology in the patient derived xenografts and relevant immunology in the syngeneic models. In this review, we focused on translational research currently in patient studies.

Visual and palpable clues are used in radical surgery to differentiate melanoma from healthy tissue and are limited to node or tumor deposits of approximately 3-5 $\mathrm{mm}$ diameter. Thus, as noted earlier many patients relapse locally in the same organ. Jinming Gao and colleagues synthesized a nanoparticle composed of polyethylene glycol-polyethylpropylaminoethyl methacrylate copolymers with attached fluorescent dye molecules and tertiary amines [141]. In the acid environment of tumor deposits, the micellar particles invert and expose the attached dye. With infrared illumination, tumors deposits as small as $1 \mathrm{~mm}$ are detected. Similar or better resolution to that obtained with cetuximab-IRDye800 [142] may occur but with better application for melanoma and other cancers. These nanoprobes will enter clinical trials in 2017 and may improve detection of small metastatic melanoma deposits at lympadenectomy and metastasectomy.

Staging tests include BRAF mutation analysis to determine patient suitability for pathway inhibitors. However, a third of BRAF mutant melanoma patients are intrinsically resistant to inhibitors. A five-gene expression profile that identifies resistant patients has been reported [143]. Combining gene expression profiles of resistant patient samples and cell lines with RNAi high throughput screening for BRAF/MEK inhibitor resistance and chromatin immunoprecipitation sequencing, a pattern of gene expression in patients was discovered that correlated with primary clinical resistance to inhibitors--Sox10-independent (Figure 5). Further testing patient's tumors with the five-gene profile and measuring BRAF inhibitor progression-free survival is underway. This will permit better therapeutic decision making in BRAF mutant metastatic melanoma patients.

Staging tests for immunotherapy response have not to date offered methods to overcome resistance. However, a novel finding may yield a low-cost method to improve efficacy. Lida and colleagues in 2013 showed germ-free or antibiotic treated tumor-bearing mice did not respond to immune or chemotherapy regimens whereas their genetically identical siblings with gut microbiota showed excellent responses that were linked to myeloid-derived macrophages that migrated from the gut to the tumor [144]. Vetizou and Sivan observed similar variations in sensitivity to anti-CTLA4 antibodies and anti-PD-L1 antibodies in tumor-bearing mice that depended upon the presence of commensal Bacteroides and Bividobacterium species, respectively [145,146]. Again, the appropriate gut bacteria induced mature intra-tumoral dendritic cells that in turn recruited and differentiated interferon $-\gamma$ producing $\mathrm{T}$ cells. Pre-treatment human gut microbiota profiles may differ in immune checkpoint responders versus non-responders and is being examined at the University of Texas Southwestern by faecal bacterial DNA metagenomic shotgun sequencing using established techniques [147]. Subsequently, quantitative PCR analyses of key bacterial species will be done and bacterial abundance quantified [148]. These experiments will provide a complete picture of specific microbial populations and how they correlate with immune checkpoint modulator treatment and response. If specific organisms yield immunotherapy sensitivity or resistance, followup intervention studies may be designed.

Sean Morrison and colleagues explored cytotoxic activity of small molecule in melanoma [149]. They found cardiac glycosides reacted with the ATP1A1 sodium/potassium pump overexpressed on melanoma cells leading to cell death. The glycosides inhibited the plasma membrane ion transporter leading to cytosolic acidification. When combined with MEK inhibitor, mitochondrial calcium increased, and mitochondrial membrane potential, ROS, NAD+ and ATP levels fell. Melanoma cell death was seen. The digoxin plus trametinib combination yielded melanoma regressions in immunocompromised mice xenografts. Based on these results, a phase $1 \mathrm{~B}$ trial of daily oral digoxin plus trametinib for $20 \mathrm{BRAF}$ wild-type melanomas patients was completed at the University of Texas Southwestern. The most common adverse events were rash, diarrhoea, nausea, and fatigue. The disease control rate including partial responses or stable disease was $13 / 20$ or $65 \%$ of patients, including $5 / 6$ or $83 \%$ for patients with NRAS mutant melanomas and $8 / 14$ or $57 \%$ for NRAS wild-type melanomas. Response

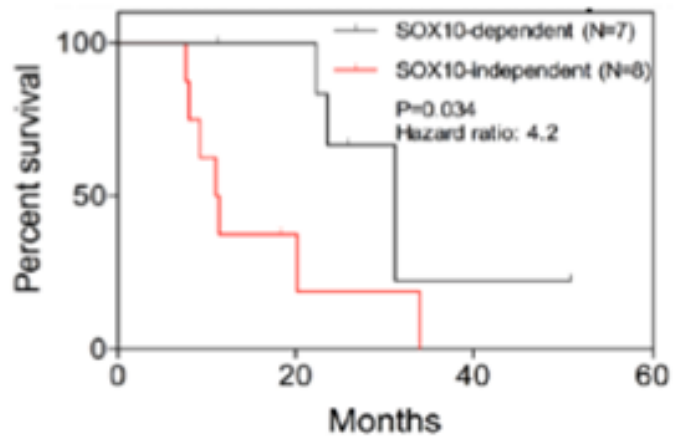

Figure 5: Dabrafenib/Vemurafenib treated patients [35]. 
durations were $2,4,6$, and 8 months for patients with partial responses, and 2, 2, 2, 4, 5, 6, 7, 8+ and 10 months for patients with stable disease. Xenografts from four patients recapitulated the treatment responses observed in patients. This compares favourably with the single agent trametinib expected $\mathrm{PR}$ rate of $10 \%$ and $\mathrm{PR}+\mathrm{SD}$ rate of $36 \%$ [39]. More patient accruals and follow-ups are needed to assess therapeutic benefit. In the subset of NRAS mutant patients, digoxin plus trametinib yielded an $83 \%$ disease control rate-DCR versus an expected rate of $58 \%$ DCR for MEK inhibitor alone [150].

While immunotherapy provides long-term disease control in many patients, up to half of patients fail to achieve clinical benefit. Immune checkpoint resistant melanomas lack intra-tumoral activated cytotoxic T lymphocytes [122]. A single modality-stereotactic ablative radiationSAbR therapy provides tumor antigens and damage-associated molecular pattern agonists to dendritic cells $[151,152]$. The stimulated and primed antigen-presenting cells induce tumor-specific cytotoxic $\mathrm{T}$ cells that migrate to the melanoma metastases and alter the tumor microenvironment [153,154]. Evidence for radiation-elicited innate immunity and enhanced immunotherapy efficacy has been shown in mouse models $[155,156]$. Further, clinical reports document cases of SAbR synergy with immune checkpoint inhibition [157-160]. In an ongoing study at the University of Texas Southwestern, metastatic melanoma patients are treated concurrently in week one with SAbR+ipilimumab+nivolumab followed by ipilimumab+nivolumab alone. Tumor biopsies are done pre-treatment and after SAbR to measure $\mathrm{T}$ cell infiltration and cGAMP levels from the cGAS-STING pathway (Figure 6) [161]. Responses will be assessed by RECISTv1.1. An increase in response rate and PFS from the historical rates of 58\% and 11.5 months is anticipated [117]. Irradiated tumors may show an increase in cGAMP levels and type I interferon gene signature postradiation secondary to cytosolic DNA and increased interferon- $\gamma$ producing tumor cytotoxic T lymphocytes secondary to macrophage/ dendritic cell chemokine secretion.

Even in the presence of CTLs permeating the melanomas and immune checkpoint blockade with anti-CTLA4 and/or anti-PD1/ PD-L1, a quarter of patients show tumor progression. Tumor cells produce indoleamine 2,3-dioxygenase-IDO [162]. IDO in the tumor microenvironment converts tryptophan to L-kynurenine (Figure 7). Tumor cytotoxic $\mathrm{T}$ cells lacking the essential amino acid tryptophan activate GCN2 leading to cell cycle arrest and functional energy [163]. Kynurenine binds aryl hydrocarbon receptors and drives de

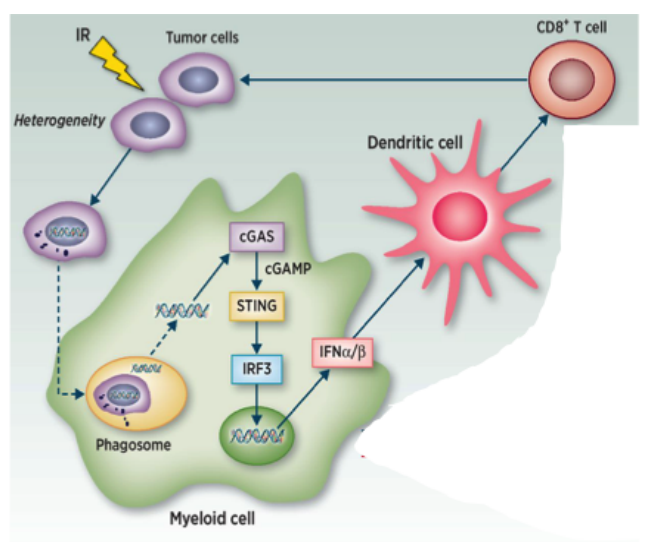

Figure 6: Stereotactic ablative radiotherapy leads to tumor $\mathrm{T}$ cell infiltration via the cGAS-cGAMP-STING pathway [17]

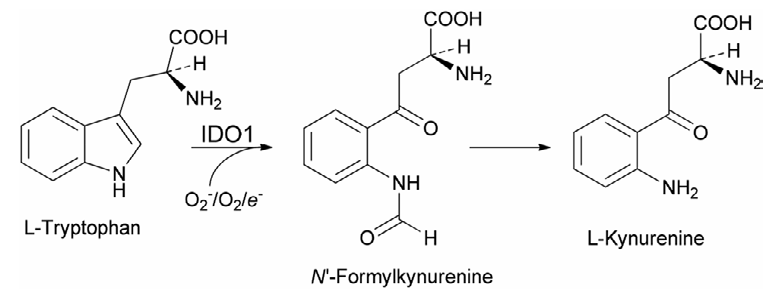

Figure 7: Indoleamine 2,3 dioxygenase-mediated tryptophan metabolism.

novo differentiation of inhibitory Foxp3+T regulatory cells-Tregs and myeloid derived suppressor cells-MDSCs. These cells, in turn, release cytokines that block recruitment of further cytotoxic T lymphocytes to the tumor. Note placental IDO blocks maternal T cell rejection of the fetus. The combination of an IDO inhibitor with immune checkpoint blockers including anti-CTLA-4 and anti-PD-1 yield additive to synergistic tumor growth inhibition in melanoma tumor models [164]. An Incyte-sponsored phase 1B study of the IDO inhibitorepacadostat with the anti-PD-1 antibody-pembrolizumab in patients with metastatic melanoma is ongoing.

Thus, current research is identifying patient subgroups for novel surgery, novel pathway inhibitors and new combinations and approaches for immunotherapy. The melanoma field is leading the way both in basic and clinical oncology science.

\section{References}

1. Howlader N, Noone AM, Krapcho M, Garshell J, Miller D, et al. (2015) SEER cancer statistics review, 1975-2012. National Cancer Institute. Bethesda, MD.

2. Andreoli MT, Mieler WF, Leiderman YI (2015) Epidemiological trends in uvea melanoma. Br J Ophthalmol 99: 1550-1553.

3. Mehra T, Grözinger G, Mann S, Guenova E, Moos R, et al. (2014) Primary localization and tumor thickness as prognostic factors of survival in patients with mucosal melanoma. PLoS One 9: e112535.

4. Davies JR, Chang YM, Bishop DT, Armstrong BK, Bataille V, et al. (2015) Development and validation of a melanoma risk score based on pooled data from 16 case-control studies. Cancer Epidemiol Biomarkers Prev 24: 8

5. Bradford PT, Goldstein AM, Tamura D, Khan SG, Ueda T, et al. (2011) Cance and neurologic degeneration in xeroderma pigmentosum: long term follow-up characterises the role of DNA repair. J Med Genet 48: 168-176.

6. Constantinescu R, Elm J, Auinger P, Sharma S, Augustine EF, et al. (2014) Malignant melanoma in early-treated Parkinson's disease: the NET-PD trial. Mov Disord 29: 263-265

7. van der Leest RJ, Liu L, Coebergh JW, Neumann HA, Mooi WJ, et al. (2012) Risk of second primary in situ and invasive melanoma in a Dutch populationbased cohort: 1989-2008. Br J Dermatol 167: 1321-1330.

8. Vogel RI, Ahmed RL, Nelson HH, Berwick M, Weinstock MA, et al. (2014) Exposure to indoor tanning without burning and melanoma risk by sunburn history. J Natl Cancer Inst 106.

9. Coghill AE, Shiels MS, Suneja G, Engels EA (2015) Elevated Cancer-Specific Mortality Among HIV-Infected Patients in the United States. J Clin Oncol 33: 2376-2383.

10. Dahlke E, Murray CA, Kitchen J, Chan AW (2014) Systemic review of melanoma incidence and prognosis in solid organ transplant recipients. Transplant Research 3: 10 .

11. Greene MH, Clark WH Jr, Tucker MA, Kraemer KH, Elder DE, et al. (1985) High risk of malignant melanoma in melanoma-prone families with dysplastic nevi. Ann Intern Med 102: 458-465.

12. Kavouras I, Tina G, Marie-Cecile C (2015) UVA and cutaneous melanoma 
incidences: spatial patterns and communities at risk. Journal of Environmental Health 77: 8-14.

13. Sanlorenzo M, Wehner MR, Linos E, Kornak J, Kainz W, et al. (2015) The risk of melanoma in airline pilots and cabin crew: a meta-analysis. JAMA Dermatol 151: 51-58.

14. Hohmann CB, Bonamigo RR, Segatto MM, Costa MM, Mastroeni S, et al. (2016) Could a specific dietary intake be a risk factor for cutaneous melanoma? Cutis 97: 421-425.

15. Vinceti M, Malagoli C, Fiorentini C, Longo C, Crespi CM, et al. Inverse association between dietary vitamin $\mathrm{D}$ and risk of cutaneous melanoma in a northern Italy population. Natr Cancer 63: 506-513

16. Han J, Colditz GA, Liu JS, Hunter DJ (2005) Genetic variation in XPD, sun exposure, and risk of skin cancer. Cancer Epidemiol Biomarkers Prev 14: 15391544.

17. Chen Q, Sun L, Chen ZJ (2016) Regulation and function of the cGAS-STING pathway of cytosolic DNA sensing. Nat Immunol 17: 1142-1149.

18. Torres SM, Luo L, Lilyquist J, Stidley CA, Flores K, et al. (2013) DNA repair variants, indoor tanning, and risk of melanoma. Pigment Cell Melanoma Res 26: 677-684.

19. Premi S, Wallisch S, Mano CM, Weiner AB, Bacchiocchi A, et al. (2015) Chemiexcitation of melanin derivatives induces DNA photoproducts long after UV exposure. Science 347: 842-847.

20. Premi S, Brash DE (2016) Chemical excitation of electrons: A dark path to melanoma. DNA Repair (Amst) 44: 169-177.

21. Holmstrom M, Lund VJ (1991) Malignant melanomas of the nasal cavity after occupational exposure to formaldehyde. $\mathrm{Br} \mathrm{J}$ Ind Med 48: 9-11.

22. Logan P, Bernabeu M, Ferreira A, Burnier MN (2015) Evidence for the Role of Blue Light in the Development of Uveal Melanoma. J Ophthalmol 2015: 386986.

23. Alexandrov LB, Nik-Zainal S, Wedge DC, Aparicio SA, Behjati S, et al. (2013) Signatures of mutational processes in human cancer. Nature 500: 415-421.

24. Thomas NE, Berwick M, Cordeiro-Stone M (2006) Could BRAF mutations in melanocytic lesions arise from DNA damage induced by ultraviolet radiation? J Invest Dermatol 126: 1693-1696.

25. Akbani R, Akdemir KC, Aksoy BA, Albert M, Ally A, et al. (2015) Genomic classification of cutaneous melanoma. Cell 161: 16

26. Woodman SE, Lazar AJ, Aldape KD, Davies MA (2012) New strategies in melanoma: molecular testing in advanced disease. Clin Cancer Res 18: 11951200.

27. Hill VK, Gartner JJ, Samuels Y, Goldstein AM (2013) The genetics of melanoma: recent advances. Annu Rev Genomics. Hum Genet 14: 257-279.

28. Huang FW, Hodis E, Xu MJ, Kryukov GV, Chin L, et al. (2013) Highly recurrent TERT promoter mutations in human melanoma. Science 339: 957-959.

29. Pavey S, Spoerri L, Haass NK, Gabrielli B (2013) DNA repair and cell cycle checkpoint defects as drivers and therapeutic targets in melanoma. Pigment Cell Melanoma Res 26: 805-816.

30. Shain AH, Yeh I, Kovalyshyn I, Sriharan A, Talevich E, et al. (2015) The Genetic Evolution of Melanoma from Precursor Lesions. N Engl J Med 373: 1926-1936.

31. Ceol CJ, Houvras Y, Jane-Valbuena J, Bilodeau S, Orlando DA, et al. (2011) The histone methyltransferase SETDB1 is recurrently amplified in melanoma and accelerates its onset. Nature 471: 513-517.

32. Kaufman CK, Mosimann C, Peng ZF, Yang S, Thomas JA, et al. (2016) A zebrafish melanoma model reveals emergence of neural crest identity during melanoma initiation. Science, In Press.

33. Begolka WS, Tsao H, Olazagasti JM, Cordoro KM, Brewer JD, et al. (2015) Early detection of melanoma: reviewing the ABCDEs. J Am Acad Dermatol 72 : 717-723.

34. Shields CL, Kels JG, Shields JA (2015) Melanoma of the eye: revealing hidden secrets, one at a time. Clin Dermatol 33: 183-196.

35. Mayer JE, Swetter SM, Fu T, Geller AC (2014) Screening, early detection, education and trends for melanoma: status (2007-2013) and future directions Part I. Epidemiology, high-risk groups, clinical strategies, and diagnostic technology. J Am Acad Dermatol 71: 59.
36. Terushkin V, Halpern AC (2009) Melanoma early detection. Hematol Oncol Clin North Am 23: 481-500.

37. Mayer JE, Swetter SM, Fu T, Geller AC (2014) Screening, early detection, education, and trends for melanoma: status (2007-2013) and future directions. Part II. Screening, education and future directions. J Am Acad Dermatol 71: 6

38. Skotarczak K, Osmola-Ma A, kowska A, Lodyga M, Polaska A, et al. (2015) Photoprotection: facts and controversies. Eur Rev Med Pharmacol Sci 19: 98-112.

39. Falchook GS, Lewis KD, Infante JR, Gordon MS, Vogelzang NJ, et al. (2012) Activity of the oral MEK inhibitor trametinib in patients with advanced melanoma: a phase 1 dose-escalation trial. Lancet Oncol 13: 782-789.

40. Bens G (2014) Sunscreens. Adv Exp Med Biol 810: 429-463.

41. Elder DE (2015) Pathology of melanoma. Surg Oncol Clin N Am 24: 229-237.

42. Longo C, Pellacani G (2016) Melanomas. Dermatol Clin 34: 411-419.

43. Goldinger SM, Courtier A, Jaberg-Bentele NF, Schindler S, Manuel M, et al. (2016) The peripheral blood TCR repertoire to facilitate patient stratification for immune checkpoint blockade inhibition in metstatatic melanoma. J Clin Oncol 34: 302.

44. Mahalingam M (2017) NF1 and Neurofibromin: Emerging Players in the Genetic Landscape of Desmoplastic Melanoma. Adv Anat Pathol 24: 1-14.

45. Doepker MP, Zager JS (2015) Sentinel lymph node mapping in melanoma in the twenty-first century. Surg Oncol Clin N Am 24: 249-260.

46. Callender GG, Gershenwald JE, Egger ME, Scoggins CR, Martin RC, et al. (2012) A novel and accurate computer model of melanoma prognosis for patients staged by sentinel lymph node biopsy. J Am Coll Surg 214: 60.

47. Soong SJ, Ding S, Coit D, Balch CM, Gershenwald JE, et al. (2010) Predicting survival outcome of localized melanoma: an electronic prediction tool based on the AJCC melanoma database. Ann Surg Oncol 17: 200.

48. Balch CM, Wilkerson JA, Murad TM, Soong SJ, Ingalls AL, et al. (1980) The prognostic significance of ulceration of cutaneous melanoma. Cancer 45: 3012 3017.

49. Balch CM, Soong SJ, Gershenwald JE, Thompson JF, Reintgen DS, et al (2001) Prognostic factors analysis of ,600 melanoma patients: validation of the American Joint Committee on Cancer melanoma staging system. J Clin Oncol 19: 3622-3634.

50. Balch CM, Soong SJ, Gershenwald JE, Thompson JF, Coit DG, et al. (2013) Age as a prognostic factor in patients with localized melanoma and regional metastases. Ann Surg Oncol 20: 3961-3968.

51. Gerami P, Cook RW, Wilkinson J, Russell MC, Dhillon N, et al. (2015) Development of a prognostic genetic signature to predict the metastatic risk associated with cutaneous melanoma. Clin Cancer Res 21: 175-183.

52. Scoggins CR, Ross MI, Reintgen DS, Noyes RD, Goydos JS, et al. (2006) Gender-related differences in outcome for melanoma patients. Ann Surg 243 693-698.

53. Harbour JW (2014)A prognostic test to predict the risk of metastasis in uveal melanoma based on a 15-gene expression profile. Methods Mol Biol 1102: 427-440.

54. Shields CL, Kaliki S, Furuta M, Fulco E, Alarcon C et al. (2015) American Joint Committee on Cancer classification of uveal melanomas (anatomic stage) predicts prognosis in 7731 patients. Ophthalmology 122: 1180.

55. Gru AA, Becker N, Dehner LP, Pfeifer JD (2014) Mucosal melanoma: correlation of clinicopathologic, prognostic, and molecular features. Melanoma Res 24 360-370.

56. Farma JM, Kulkarni N, Hsu C (2015) Surgical management of primary and recurrent melanoma. Surg Oncol Clin N Am 24: 239-247.

57. Shields JA, Shields CL (2015) Management of posterior uveal melanoma. Ophthalmol 122: 4

58. Sikuade MJ, Salvi S, Rundle PA, Errington DG, Kacperek A, et al. (2015) Outcomes of treatment with stereotactic radiosurgery or proton beam therapy for choroidal melanoma. Eye (Lond) 29: 1194-1198.

59. Shi H, Wu J, Zhijian J, Chen C (2015) Molecular basis for the specific recognition of the metazoan cyclic GMP-AMP by the innate immune adaptor protein STING. Proc Natl Acad Sci 1: 8947-8948. 
60. Nobbenhuis MA, Lalondrelle S, Larkin J, Banerjee S (2014) Management of melanomas of the gynaecological tract. Curr Opin Oncol 26: 508-513.

61. Nam S, Kim CW, Baek SJ, Hur H, Min BS, et al. (2014) The clinical features and optimal treatment of anorectal malignant melanoma. Ann Surg Treat Res 87: 113-117.

62. Morton DL, Thompson JF, Cochran AJ, Mozzillo N, Nieweg OE, et al. (2014) Final trial report of sentinel-node biopsy versus nodal observation in melanoma. N Engl J Med 370: 599-609.

63. Diller ML, Martin BM, Delman KA (2015) Lymph node dissection for stage II melanoma. Surg Oncol Clin N Am 24: 261-277.

64. Leiter U, Stadler R, Mauch C, Hohenberger W, Brockmeyer N, et al. (2016) Complete lymph node dissection versus no dissection in patients with sentinel lymph node biopsy positive melanoma (DeCOG-SLT): a multicentre, randomised, phase 3 trial. Lancet Oncol 17: 757-767.

65. Burmeister BH, Henderson MA, Ainslie J, Fisher R, Di lulio J, et al. (2012) Adjuvant radiotherapy versus observation alone for patients at risk of lymphnode field relapse after therapeutic lymphadenectomy for melanoma: a randomised trial. Lancet Oncol 13: 589-597.

66. Meng XJ, Hua-Fei A, Wei-Ting, Huang F, ChenXi CS, et al. (2014) Impact of different surgical and postoperative adjuvant treatment modalities on survival of sinonasal malignant melanoma. BMC Cancer 14: 60.

67. Rafique I, Kirkwood JM, Tarhini AA (2015) Immune checkpoint blockade and interferon-Ît in melanoma. Semin Oncol 42: 436-447.

68. Mocellin S, Pasquali S, Rossi CR, Nitti D (2010) Interferon alpha adjuvant therapy in patients with high-risk melanoma: a systematic review and metaanalysis. J Natl Cancer Inst 102: 493-501.

69. Eggermont AM, Suciu S, Testori A, Kruit WH, Marsden J, et al. (2012) Ulceration and stage are predictive of interferon efficacy in melanoma: results of the phase III adjuvant trials EORTC 18952 and EORTC 18991. Eur J Cancer 48: 218-225.

70. Kepp O, Senovilla L, Vitale I, Vacchelli E, Adjemian S, et al. (2014) Consensus guidelines for the detection of immunogenic cell death. Oncoimmunology 3 : e955691.

71. Daud A, Soon C, Dummer R, EggermontAM, Hwu WJ, et al. (2012) Management of pegylated interferon alpha toxicity in adjuvant therapy of melanoma. Expert Opin Biol Ther 12: 1087-1099.

72. Kleffel S, Posch C, Barthel SR, Mueller H, Schlapbach C, et al. (2015) Melanoma Cell-Intrinsic PD-1 Receptor Functions Promote Tumor Growth. Cell 162: $1242-1256$

73. Eggermont AMM, Chiarion-Sileni V, Grob JJ, Dummer R, Wolchok JD, et al (2015) Adjuvant ipilimumab versus placebo after complete resectio of high-risk stage III melanoma (EORTC18071). Lancet Oncology 16: 52.

74. Pawlik TM, Ross MI, Johnson MM, Schacherer CW, McClain DM, et al. (2005) Predictors and natural history of in-transit melanoma after sentine lymphadenectomy. Ann Surg Oncol 12: 587-596.

75. Weide B, Faller C, Büttner P, Pflugfelder A, Leiter U, et al. (2013) Prognostic factors of melanoma patients with satellite or in-transit metastasis at the time of stage III diagnosis. PLoS One 8: e63137.

76. John HE, Mahaffey PJ (2014) Laser ablation and cryotherapy of melanoma metastases. J Surg Oncol 109: 296-300.

77. Nieweg OE, Kroon BB (2014) Isolated limb perfusion with melphalan for melanoma. J Surg Oncol 109: 332-337.

78. Temple-Oberle CF, Byers BA, Hurdle V, Fyfe A, McKinnon JG (2014) Intra-lesional interleukin-2 therapy for in transit melanoma. J Surg Oncol 109: 327-331.

79. Deutsch GB, Kirchoff DD, Faries MB (2015) Metastasectomy for stage IV melanoma. Surg Oncol Clin N Am 24: 279-298.

80. Howard JH, Thompson JF, Mozzillo N, Nieweg OE, Hoekstra HJ, et al. (2012) Metastasectomy for distant metastatic melanoma: analysis of data from the first Multicenter Selective Lymphadenectomy Trial (MSLT-I). Ann Surg Oncol 19: 2547-2555

81. Goyal S, Silk AW, Tian S, Mehnert J, Danish S, et al. (2015) Clinica Management of Multiple Melanoma Brain Metastases: A Systematic Review. JAMA Oncol 1: 668-676.

82. Sahgal A, Aoyama H, Kocher M, Neupane B, Collette S, et al. (2015) Phase 3 trials of stereotactic radiosurgery with or without whole-brain radiation therapy for 1 to 4 brain metastases: individual patient data meta-analysis. Int J Radiat Oncol Biol Phys 91: 710-717.

83. Liu Y, Alexander BM, Chen YH, Horvath MC, Aizer AA, et al. (2015) Salvage whole brain radiotherapy or stereotactic radiosurgery after initial stereotactic radiosurgery for 1-4 brain metastases. J Neurooncol 124: 429-437.

84. Frakes JM, Figura NB, Ahmed KA, Juan TH, Patel N, et al. (2015) Potentia role for LINAC-based stereotactic radiosurgery for the treatment of 5 or more radioresistant melanoma brain metastases. J Neurosurg Epub 123: 1261-1267.

85. Sperduto PW, Shanley R, Luo X, Andrews D, Werner-Wasik M, et al. (2014) Secondary analysis of RTOG 950 , a phase 3 randomized trial of whole-brain radiation therapy versus WBRT plus stereotactic radiosurgery in patients with 1-3 brain metastases. Int J Radiat Onc Biol Phys 90: 52.

86. Avril MF, Aamdal S, Grob JJ, Hauschild A, Mohr P, et al. (2004) Fotemustine compared with dacarbazine in patients with disseminated malignant melanoma: a phase III study. J Clin Oncol 22: 1118-1125.

87. Hersh EM, Day OSJ, Ribas A, Samlowski WE, Gordon MS, et al. (2010) A phase 2 clinical trial of nab-paclitaxel in previously treated and chemotherapynaive patients with metastatic melanoma. Cancer 116: 155-163.

88. Kottschade LA, Suman VJ, Amatruda T, McWilliams RR, Mattar BI, et al. (2011) A phase II trial of Nab-paclitaxel and carboplatin in patients with unresectable stage IV melanoma. Cancer 117: 170.

89. Ott PA, Hamid O, Pavlick AC, Kluger H, Kim KB, et al. (2014) Phase I/II study of the antibody-drug conjugate glembatumumab vedotin in patients with advanced melanoma. J Clin Oncol 32: 3659-3666.

90. Patel PM, Suciu S, Mortier L, Kruit WH, Robert C, et al. (2011) Extended schedule, escalated dose temozolomide versus dacarbazine in stage IV melanoma: results of a randomised phase III study (EORTC 18032). Eur J Cancer 47: 1476-1483.

91. Tuominen $R$, Jewell $R$, van den Oord JJ, Wolter $P$, Stierner $U$, et al. (2015) MGMT promoter methylation is associated with temozolomide response and prolonged progression-free survival in disseminated cutaneous melanoma. In J Cancer 136: 284

92. Villaruz LC, Huang G, Romkes M, Kirkwood JM, Buch SC et al. (2015) MicroRNA expression profiling predicts clinical outcome of carboplatin/ paclitaxel-based therapy in metastatic melanoma treated on the ECOG-ACRIN trial E2603. Clin Epigenetics 7: 58.

93. Grimaldi AM (2015) Novel mechanisms and therapeutic approaches in melanoma. Discovery Medicine 19: 45.

94. Trinh VA, You Y, Hwu WJ (2014) Treatment of BRAF-mutated advanced cutaneous melanoma. Chin Clin Oncol 3: 28.

95. Johannessen CM, Boehm JS, Kim SY, Thomas SR, Wardwell L, et al. (2010) COT/MAP3K8 drives resistance to RAF inhibition through MAP kinase pathway reactivation. Nature 468: 96 .

96. Montagut C, Sharma SV, Shioda T, McDermott U, Ulman M, et al. (2008) Elevated CRAF as a potential mechanism of acquired resistance to BRAF inhibition in melanoma. Cancer Res 68: 4853-4861.

97. Wagle N, Allen EMV, Treacy DJ, Frederick DT, Cooper ZA, et al. (2014) MAP kinase pathway alterations in BRAF-mutant melanoma patient with acquired resistance to combined RAF/MEK inhibition. Cancer Discovery 4: 61-68.

98. Watson IR, Li L, Cabeceiras PK, Mahdavi M, Gutschner T, et al. (2014) The RAC1 P29S hotspot mutation in melanoma confers resistance to pharmacological inhibition of RAF. Cancer Res 74: 4845-4852.

99. Shi H, Hong A, Kong X, Koya RC, Song C, et al. (2014) A novel AKT1 mutant amplifies an adaptive melanoma response to BRAF inhibition. Cancer Discov 4: 69-79.

100. Straussman R, Morikawa T, Shee K, Barzily-Rokni M, Qian ZR, et al. (2012) Tumor micro-environment elicits innate resistance to RAF inhibitors through HGF secretion. Nature 487: 500

101. Cao J, Heijkants RC, Jochemsen AG, Dogrusöz M, de Lange MJ, et al. (2016) Targeting of the MAPK and AKT pathways in conjunctival melanoma shows potential synergy. Oncotarget.

102. Heppt MV, Tietze JK, Graf SA, Berking C (2015) Combination therapy of melanoma using kinase inhibitors. Curr Opin Oncol 27: 134-140. 
Citation: Frankel AE, Frenkel EP (2017) Melanoma Metamorphoses: Advances in Biology and Therapy. J Cancer Sci Ther 9: 325-335. doi: 10.4172/1948-5956.1000437

103. Penna I, Molla A, Grazia G, Cleris L, Nicolini G, et al. (2016) Primary crossresistance to BRAFV600E-, MEK1/2- and PI3K/mTOR-specific inhibitors in BRAF-mutant melanoma cells counteracted by dual pathway blockade. Oncotarget 7: 3947-3965.

104. Wei BR, Michael HT, Halsey CH, Peer CJ, Adhikari A, et al. (2016) Synergistic targeted inhibition of MEK and dual PI3K/mTOR diminishes viability and inhibits tumopr growth of canine melanoma underscoring its utility as a preclinical model for human mucosal melanoma. Pigment Cell Melanoma Res 29: 643-655.

105. Konieczkowski DJ, Johannessen CM, Abudayyeh O, Kim JW, Cooper ZA, et al. (2014) A melanoma cell state distinction influences sensitivity to MAPK pathway inhibitors. Cancer Discovery 4: 816-827.

106. Van Allen EM, Wagle N, Sucker A, Treacy DJ, Johannessen CM, et al. (2014) The genetic landscape of clinical resistance to RAF inhibition in metastatic melanoma. Cancer Discovery 4: 94-109.

107. Guo J, Si L, Kong Y, Flaherty KT, Xu X, et al. (2011) Phase II, open-label, single-arm trial of imatinib mesylate in patients with metastatic melanoma harboring c-Kit mutation or amplification. J Clin Oncol 29: 2904-2909.

108. Rapisuwon S, Parks K, Al-Refaie W, Atkins MB (2014) Novel somatic KIT exon 8 mutation with dramatic response to imatinib in a patient with mucosal melanoma: a case report. Melanoma Res 24: 509-511.

109. Kim KB, Sosman JA, Fruehauf JP, Linette GP, Markovic SN, et al. (2012) BEAM: a randomized phase II study evaluating the activity of bevacizumab in combination with carboplatin plus paclitaxel in patients with previously untreated advanced melanoma. J Clin Oncol 30: 34-41.

110. Bramhall RJ, Mahady K, Peach AH (2014) Spontaneous regression of metastatic melanoma - clinical evidence of the abscopal effect. Eur J Surg Oncol 40: 34-41.

111. Ruocco MG, Pilones KA, Kawashima N, Cammer M, Huang J, et al. (2012) Suppressing $T$ cell motility induced by anti-CTLA-4 monotherapy improves antitumor effects. J Clin Invest 122: 3718-3730.

112. Spangler JB, Moraga I, Mendoza JL, Garcia KC (2015) Insights into cytokinereceptor interactions from cytokine engineering. Annu Rev Immunol 33: 139-167.

113. Petrella T, Quirt I, Verma S, Haynes AE, Charette M, et al. (2007) Single-agent interleukin-2 in the treatment of metastatic melanoma: a systematic review. Cancer Treat Rev 33: 484-496.

114. Payne R, Glenn L, Hoen H, Richards B, Smith JW 2nd, et al. (2014) Durable responses and reversible toxicity of high-dose interleukin-2 treatment of melanoma and renal cancer in a Community Hospital Biotherapy Program. J Immunother Cancer 2: 13.

115. Joseph RW, Sullivan RJ, Harrell R, Stemke-Hale K, Panka D, et al. (2012) Correlation of NRAS mutations with clinical response to high-dose IL-2 in patients with advanced melanoma. J Immunother 35: 66-72.

116. Seung SK, Curti BD, Crittenden M, Walker E, Coffey T, et al. (2012) Phase 1 study of stereotactic body radiotherapy and interleukin-2--tumor and immunological responses. Sci Transl Med 4: 137ra74.

117. Larkin J, Hodi FS, Wolchok JD (2015) Combined nivolumab and ipilimumab or monotherapy in untreated melanoma. New England J Med 373: 1270-1271.

118. Horvat TZ, Adel NG, Dang TO, Momtaz P, Postow MA, et al. (2015) Immunerelated adverse events, need for systemic immunosuppression, and effects on survival and time to treatment failure in patients with melanoma treated with ipilimumab at Memorial Sloan Kettering Cancer Center. J Clin Oncol 33: 3193-3198.

119. Chiappinelli KB, Strissel PL, Desrichard A, Li H, Henke C, et al. (2015) Inhibiting DNA methylation causes an interferon response in cancer vis dsRNA including endogenous retroviruses. Cell 162: 974-986.

120.Diem S, Kasenda B, Martin-Liberal J, Lee A, Chauhan D, et al. (2015) Prognostic score for patients with advanced melanoma treated with ipilimumab. Eur J Cancer 51: 2785-2791.

121. Funt S, Charen AS, Yusko E, Vignali M, Benzeno S, et al. (2016) Correlation of peripheral and intratumor T-cell receptor clonality with clinical outcomes in patients with metastatic urothelial cancer ( $\mathrm{mUC}$ ) treated with atezolizumab. J Clin Oncol 34 Suppl: 300.

122. Herbst RS, Soria JC, Kowanetz M, Fine GD, Hamid O, et al. (2014) Predictive correlates of response to the anti-PD-L1 antibody MPDL3280A in cancer patients. Nature 515: 563-567.
123. Higgs BW, Morehouse C, Streicher K, Rebelatto MC, Steele K, et al. (2016) Relationship of baseline tumoral IFNg mRNA and PD-L1 protein expression to overall survival in durvalumab-treated NSCLC patients. J Clin Oncol 34 Suppl: 303.

124. Hugo W, Zaretsky JM, Sun L, Song C, Moreno BH, et al. (2016) Genomic and Transcriptomic Features of Response to Anti-PD-1 Therapy in Metastatic Melanoma. Cell 165: 35-44.

125.Johnson DB, Lovly CM, Flavin M, Panageas KS, Ayers GD, et al. (2015) Impact of NRAS mutations for patients with advanced melanoma treated with immune therapies. Cancer Immunol Res 3: 288-295.

126. Martens A, Wistuba-Hamprecht K, Foppen MG, Yuan J, Postow MA, et al. (2016) Baseline periopheral blood biomarkers associated with clinical outcome of advanced melanoma patients treated with ipilimumab. Clin Cancer Res 22: 2908-2918.

127. McGranahan N, Furness AJ, Rosenthal R, Ramskov S, Lyngaa R, et al. (2016) Clonal neoantigens elicit $T$ cell immunoreactivity and sensitivity to immune checkpoint blockade. Science 351: 1463-1469.

128. Snyder A, Makarov V, Merghoub T, Yuan J, Zaretsky JM, et al. (2014) Genetic basis for clinical response to CTLA-4 blockade in melanoma. N Engl J Med 371: 2189-2199.

129.Spranger S, Bao R, Gajewski TF (2015) Melanoma-intrinsic $\hat{I}^{2}$-catenin signalling prevents anti-tumour immunity. Nature 523: 231-235.

130. Tumeh PC, Harview CL, Yearley JH, Shintaku IP, Taylor EJ, et al. (2014) PD-1 blockade induces responses by inhibiting adaptive immune resistance. Nature 515: 568-571.

131. Weide B, Martens A, Hassel JC, Berking C, Postow MA, et al. (2016) Baseline Biomarkers for Outcome of Melanoma Patients Treated with Pembrolizumab. Clin Cancer Res 22: 5487-5496.

132. Yuan J, Zhou J, Dong Z, Tandon S, Kuk D, et al. (2014) Pre-treatment serum VEGF is associated with clinical response and overall survival in advanced melanoma patients treated with ipilimumab. Cancer Immunol Res 2:127-132.

133.Zaretsky JM, Garcia-Diaz A, Shin DS, Escuin-Ordinas H, Hugo W, et al. (2016) Mutations Associated with Acquired Resistance to PD-1 Blockade in Melanoma. N Engl J Med 375: 819-829.

134.Algazi AP, Tsai KK, Shoushtari AN, Munhoz RR, Eroglu Z, et al. (2016) Clinical outcomes in metastatic uveal melanoma treated with PD-1 and PD-L1 antibodies. Cancer 122: 3344-3353.

135. Shoushtari AN, Munhoz RR, Kuk D, Ott PA, Johnson DB, et al. (2016) The efficacy of anti-PD-1 agents in acral and mucosal melanoma. Cancer 122 3354-3362.

136. Sullivan R, LoRusso P, Boerner S, Dummer R (2015) Achievements and challenges of molecular targeted therapy in melanoma. ASCO Educational Book 2015: 177-186.

137. Andtbacka RHI, Kaufman HL, Collichio F, Amatruda T, Senzer N, et al. (2015) Talimogene laherparepvec improves durable response rates in patients with advanced melanoma. J Clin Oncol 33: 2780-2788.

138. Carita G, Némati F, Decaudin D (2015) Uveal Melanoma Patient-Derived Xenografts. Ocul Oncol Pathol 1: 161-169.

139. Kuzu OF, Nguyen FD, Noory MA, Sharma A (2015) Current State of Animal (Mouse) Modeling in Melanoma Research. Cancer Growth Metastasis 8: 81-94.

140. Thompson JF, Soong SJ, Balch CM, Gershenwald JE, Ding S, et al. (2011) Prognostic significance of mitotic rate in localized primary cutaneous melanoma: an analysis of patients in the multi-institutional American Joint Committee on Cancer melanoma staging database. J Clin Oncol 29: 21992205.

141.Zhao T (2015) Tumor acidosis imaging advances cancer staging and detection. Science.

142. Warram JM, de Boer E, Moore LS, Schmalbach CE, Withrow KP, et al. (2015)A ratiometric threshold for determining presence of cancer during fluorescenceguided surgery. J Surg Oncol 112: 2-8.

143. Eskiocak B (2015) Biomarker accessible and chemically addressable mechanistic subtypes of BRAF melanoma. Cell.

144. Lida N, Dzutsev A, Stewart CA, Smith L, Bouladoux N, et al. (2013) Commensal bacterial control cancer response to therapy by modulating the tumor microenvironment. Science 3: 967-970. 
Citation: Frankel AE, Frenkel EP (2017) Melanoma Metamorphoses: Advances in Biology and Therapy. J Cancer Sci Ther 9: 325-335. doi: 10.4172/1948-5956.1000437

145. Sivan A, Corrales L, Hubert N, Williams JB, Aquino-Michaels K, et al. (2015) Commensal Bifidobacterium promotes antitumor immunity and facilitates antiPD-L1 efficacy. Science 350: 1084-108.

146. Vétizou $M$, Pitt JM, Daillère $R$, Lepage $P$, Waldschmitt $N$, et al. (2015) Anticancer immunotherapy by CTLA-4 blockade relies on the gut microbiota. Science 350: 1079-1084

147.Fan D, Coughlin LA, Neubauer MM, Kim J, Kim MS, et al. (2015) Activation of HIF-1a and LL-37 by commensal bacteria inhibits Candida albicans colonization. Nat Med 21: 808-814.

148. Vaishnava S, Yamamoto M, Severson KM, Ruhn KA, Yu X, et al. (2012) The antibacterial lectin Reglllgamma promotes the spatial segregation of microbiota and host in the intestine. Science 33: 255-258.

149. Eskiocak U (2016) Combinational effects of ion transporters and MAP kinase pathway inhibitors in melanoma. Nature Communications, In press.

150.Dummer R, Schadendorf D, Ascierto PA, Fernández AMA, Dutriaux C, et al (2016) Results of NEM: a phase III trial of binimetinib (BINI) vs dacarbazine (DTIC) in NRAS-mutant cutaneous melanoma. J Clln Oncol 34 Suppl: 9500.

151. Kulzer L, Rubner Y, Deloch L, Allgäuer A, Frey B, et al. (2014) Norm- and hypo-fractionated radiotherapy is capable of activating human dendritic cells. J Immunotoxicol 11: 328-336.

152. Rubner Y, Wunderlich R, Rühle PF, Kulzer L, Werthmöller N, et al. (2012) How does ionizing irradiation contribute to the induction of anti-tumor immunity? Front Oncol 2: 75

153. Lim JY, Gerber SA, Murphy SP, Lord EM (2014) Type I interferons induced by radiation therapy mediate recruitment and effector function of CD8+ $T$ cells. Cancer Immunol Immunother 63: 259-271.

154. Sharabi AB, Nirschl CJ, Kochel CM, Nirschl TR, Francica BJ, et al. (2015) Stereotactic radiation therapy augments antigen-specific $\mathrm{PD}-1$-mediated antitumor immune responses via cross-presentation of tumor antigen. Cancer Immunol Res 3: 345-355.
155.Demaria S, Ng B, Devitt ML, Babb JS, Kawashima N, et al. (2004) lonizing adiation inhibition of distant untreated tumors (abscopal effect) is immune mediated. Int J Radiat Oncol Biol Phys 5: 862-870.

156. Twyman-Saint VC, Rech AJ, Maity A, Rengan R, Pauken KE, et al. (2015) Radiation and dual checkpoint blockade activate non-redundant immune mechanisms in cancer. Nature 520: 373-377.

157. Barker CA, Postow MA (2014) Combinations of radiation therapy and immunotherapy for melanoma: a review of clinical outcomes. Int J Radiat Oncol Biol Phys 88: 986-997.

158. Deng L, Liang H, Xu M, Yang X, Burnette B, et al. (2014) STING-dependent cytosolic DNA sensing promotes radiation-induced type I interferon-dependent anti-tumor immunity in immunogenic tumors. Immunity 4: 843-852.

159. Postow MA, Callahan MK, Barker CA, Yamada Y, Yuan J, et al. (2012) Immunologic correlates of the abscopal effect in a patient with melanoma. $\mathrm{N}$ Engl J Med 366: 925-931.

160. Salama AK, Postow MA, Salama JK (2016) Irradiation and immunotherapy: From concept to the clinic. Cancer 122: 1659-1671.

161. Shi W (2015) Role for radiation therapy in melanoma. Surg Oncol Clin N Am 24: 323-335.

162. Holmgaard RB, Zamarin D, Li Y, Gasmi B, Munn DH, et al. (2015) TumorExpressed IDO Recruits and Activates MDSCs in a Treg-Dependent Manner Cell Rep 13: 412-424.

163. Munn DH, Mellor AL (2013) Indoleamine ,3 dioxygenase and metabolic control of immune responses. Trends Immunol 34: 137-143.

164.Spranger S, Koblish HK, Horton B, Scherle PA, Newton R, et al. (2014) Mechanism of tumor rejection with doublets of CTLA-, PD-1/PD-L, or IDO blockade involves restored IL-2 production and proliferation of CD8(+) T cells directly within the tumor microenvironment. J Immunother Cancer 2: 3. 